\section{P-27 THE LIFE STORY PROJECT: A REPARATIVE PROCESS}

Ruth Jolley, Kacey Leader. St Margaret's Hospice, Somerset, UK

10.1136/bmjspcare-2017-hospice.54

Life story work with people approaching end of life offers more than an opportunity to record a person's history: it offers time to reflect, make sense, and reframe. Supported by a life story volunteer, loss and change are acknowledged and often remain central to their narrative. Yet the focus is on people's lives, who they are, and what they have achieved. People articulate what is most important to them; their life is celebrated. It is a reparative process: people create and share their legacy looking to the past, the present and the future. The project has created a lasting, audible and visual archive of the patient's life providing thoughts and memories for families to share. This presentation will draw on the literature and evidence base of narrative medicine. It describes the hospice Life Story pilot, people's experience, and what we have learned from participants and our evaluation. We will illustrate this with vignettes, and how the project is being rolled out in the county. We will conclude with methodological and practice development opportunities, and key research questions.

\section{P-28 THE ART OF DYING WELL}

Margaret Doherty. Art of Dying Well, London, UK

10.1136/bmjspcare-2017-hospice.55

The Catholic Church in England and Wales has brought the medieval manuscript Ars Moriendi - The Art of Dying - into the digital age, with a website -www.artofdyingwell.org aimed at helping terminally ill people and their loved ones deal with death. Like the original 15th century work, The Art of Dying Well is intended to bring spiritual comfort and to offer practical guidance to people in the final stage of life. The modern - day version offers videos, animations and interviews with terminally ill people and their carers.

Who is it for?

- People who are dying

- People with a friend or relative who is dying/has died

- People who care for the dying in a professional context

- People who are surviving death, or battling a life threatening disease

The national conversation around death As well as developing the Art of Dying Well website and engaging in the digital conversation around death, the Art of Dying Well initiative is taking part in the national conversation around death and helping to raise 'literacy levels' on the topic of dying well and appreciation of spiritual care in the process. To date, the Art of Dying Well has and continues to receive significant coverage in the Guardian, Times, LBC radio, BBC News, BBC Five Live, BBC Radio 2, Vatican Radio, and the Catholic press.

What People Say 'It speaks powerfully into this awkward, immature silence around death. And I believe it has the potential to alleviate much suffering. I've seen it used with clinicians, families and patients. And I have seen it be a powerful help.' Jim McManus, Director of Public Health, Hertfordshire County Council.

\section{P-29 \\ DE WE PREPARE OUR PATIENTS FOR THEIR DIGITAL LEGACY?}

${ }^{1,2}$ Hazel Coop, ${ }^{1,2}$ Clare Marlow. ${ }^{1}$ WM CARES, Birmingham, UK; ${ }^{2}$ The Royal Wolverhampton NHS TRUST, Wolverhampton, UK

10.1136/bmjspcare-2017-hospice.56

Background Digital legacy is the digital content that we leave after death. Social media is becoming a more prominent part of our everyday lives. A recent report found that 94\% digital consumers, aged 16-64, have at least one social media account, with one in every three minutes online devoted to social networking (GWI Social, 2017). It has been predicted that by 2098 Facebook could be the biggest virtual graveyard (The Telegraph, 2016). It is a forum where palliative care is prominent with 685500 tweets in a two-year period relating to palliative care, from both health care professionals and the general public. (Nwosu et al, 2015). It has been seen as beneficial for a specialist palliative care team to gain insight to how a patient is feeling through their blog (Lowney \& O’Brien, 2012). Dr. Kate Granger used social media to document her journey, which has given a unique insight of a doctor living with a terminal illness (Granger, 2014). However, use of social media can also have negative consequences; a father felt his son's dying process had been violated by friends setting up a Facebook page to raise money for his children's future school fees (Smith, 2011). The Digital Legacy Association - https://digitallegacyassociation.org/ - has produced a public awareness leaflet to help drive the importance of digital legacy forward, but as health care professionals do we assist this?

Question How well do we as palliative care professionals prepare patients for their digital legacy?

Methods An online questionnaire will be sent to doctors, nurses and social workers working at hospices within the West Midlands which they are asked to complete and submit within six weeks. The questionnaire asks about: their own use of social media; if they have thought about their own digital legacy; whether they have discussed digital legacy with a patient and, if so, what stimulated that conversation.

Results The results are pending and will be complete by August 2017.

\section{P-30 CHANGING ATTITUDES AND BEHAVIOURS TOWARDS DIGITAL LEGACY AND DIGITAL ASSETS}

${ }^{1}$ James Norris, ${ }^{2}$ Mark Taubert. ${ }^{1}$ Digital Legacy Association, London, UK; ${ }^{2}$ Velindre NHS Trust, Cardiff, UK

10.1136/bmjspcare-2017-hospice.57

Background The Internet is the biggest and most 'disruptive' force since the industrial revolution. As a result, society is spending an ever increasing amount of time online. This has led to a range of benefits whilst changing the way in which society prepares for death, mourns and remembers the deceased into posterity. Each year the Digital Legacy Association carry out the Digital Death Survey.

Aims The aim of the Digital Death Survey is to explore society's attitudes towards death and dying in today's digital world. Asking questions through such a survey and openly publishing the results helps evoke discussions around 'digital death' and the implications not planning for death digitally 